\title{
Case Report by Awad and Coworkers
}

\section{Thomas Krasemann}

Published online: 25 August 2009

(C) Springer Science+Business Media, LLC 2009

With great interest I read the case report by Awad and coworkers about the fascinating large outpouching of the left ventricle. I agree that it is very difficult to name it either as a diverticulum (although it seems contractile, which to my understanding is the main criterion for distinguishing between diverticula and aneurysms [1]) or as a double-chambered left ventricle.

The size of the structure is almost as large as the true left ventricular chamber, and the connection is wide. Thus, both parts of the cavity act as one. For patients with ischemic dilated cardiomyopathy, surgical ventricular restoration has been used to reduce the size of dilated ventricles, with this decrease in tension on the myocardium leading to better contractility $[2,3]$. In this view, cardiac transplantation may not be the only treatment option for the reported child. Excision of the outpouching may improve or even normalize left ventricular contractility.

\section{References}

1. Krasemann T, Gehrmann J, Fenge H et al (2001) Ventricular aneurysm or diverticulum? Clinical differential diagnosis. Pediatr Cardiol 22:409-411

2. Castelvecchio S, Menicanti L, Ranucci M et al (2008) Impact of surgical ventricular restoration on diastolic function: implications of shape and residual ventricular size. Ann Thorac Surg 86:18491854

3. Tulner SA, Bax JJ, Bleeker GB et al (2006) Beneficial hemodynamic and clinical effects of surgical ventricular restoration in patients with ischemic dilated cardiomyopathy. Ann Thorac Surg 82:1721-1727

T. Krasemann $(\bowtie)$

Evelina Children's Hospital,

Guy's \& St. Thomas' NHS Foundation Trust,

Westminster Bridge Road, London SE1 7EH, UK

e-mail: Thomas.Krasemann@gstt.nhs.uk 